\title{
Left Hepatic Artery Arising from the Superior Mesenteric Artery: A Case Study of a Rare Anatomic Variation
}

\author{
Eleazar Chaib*, Yngrid E.D.M. de Souza, Marcelo Y. Maruyama, Leonardo F.B. Marinucci, \\ Matheus R. Aranha, Isabela A. de Siqueira, Lucas Chen, Mariana P.D. de Campos Carvalho \\ and Luiz A.C. D’Albuquerque
}

Liver Transplantation Unit, and LIM37, Department of Gastroenterology, University of São Paulo School of Medicine, São Paulo, Brazil

\begin{abstract}
Knowledge of hepatic arterial vascularization and its variations have a significant relevance for the daily practice of hepato-biliary surgeon as well as radiologists. Human cadaver livers $(n=60)$ were obtained from routine autopsies. Resections were carried out en bloc with liver, celiac trunk (CT), left gastric artery (LGA), lesser omentum, superior mesenteric artery (SMA) and head of the pancreas. We have found one case with an exceptional anatomic variation, replaced left hepatic artery (LHA) coming off the SMA directly to the hepatic left lobe. We would like to draw attention for this particularly anatomic variation of the origin of the LHA ensuring that no damage will be made during gastrointestinal surgery.
\end{abstract}

Keywords: Liver anatomy, left hepatic anomaly, superior mesenteric artery.

\section{INTRODUCTION}

Knowledge of hepatic arterial vascularization and its variations have a significant relevance for the daily practice, basically the classic arterial anatomy is seen in 55 to $77 \%$ of the population $[1,2]$. Anatomical variations of the arterial supply of the liver are reported to occur in $25-50 \%$ of the total population [3].

The most common variations of the left hepatic artery (LHA) origin are: from left gastric artery (LGA) - 25\% [4, 5], splenic and gastroduodenal artery - 4\% [6] and directly from the aorta $-0.5-2 \%$ [6-9].

Our goal is to highlight the importance of knowing the hepatic artery anatomy and its variations since we have found an exceptional replaced LHA arising from the superior mesenteric artery (SMA).

\section{MATERIAL AND METHODS}

Human cadaver livers $(n=60)$ were obtained from routine autopsies. The cadavers and the livers had to comply with the following requirements: (1) minimum age 18 years old, (2) no liver pathology to be expected from medical history and, (3) no liver pathology noted at the autopsy.

The Research and Ethical Committee of the University of Sao Paulo School of Medicine approved the human cadaver research.

Resections were carried out en bloc with liver, celiac axis, left gastric artery, lesser omentum, superior mesenteric artery and pancreas head. An eventual left or right hepatic artery was thus taken down in continuity with the aorta. The

*Address correspondence to this author at the Liver Transplantation Unit, and LIM 37, Hospital das Clinicas, Av. Dr. Enéas de Carvalho Aguiar 255, Level 9, CEP 05403-010, Sao Paulo, Brazil; Tel: 55-11-3061.8322; Fax: 5511-30617270; E-mail: eleazarchaib@yahoo.co.uk liver was dissected free from its peritoneal attachments. The hepato-duodenal ligament was dissected as close to the duodenum as possible. The gallbladder, if present, was removed.

In the division of right and left lobes of the liver it was necessary to excise the caudate lobe (segment I). The cutting plane of the liver consisted of a longitudinal section made immediately on the left of the supra-hepatic inferior vena cava through the gallbladder bed preserving the arterial, portal and biliary branches in order to obtain two viable grafts (right lobe - segments V,VI,VII,VIII and left lobe segments II,III,IV) as defined by the main portal scissure. The hepatic artery was dissected out and recorded carefully when the liver was split in right and left lobe.

\section{RESULTS}

We have found right and left hepatic artery in 45(75\%) cases; replaced or accessory LHA arising from the LGA in $9(15 \%)$ cases; replaced or accessory right hepatic artery (RHA) originating from the SMA in $4(6.6 \%)$ cases; the right hepatic artery coming from the SMA in 15 (25\%) cases; the left hepatic artery originating from the LGA in $2(3.3 \%)$ cases; the entire CHA arising as a branch of the SMA in 1 $(1.6 \%)$ case; the CHA originating directly from the aorta in $11(18.3 \%)$ cases; accessory RHA from SMA and replaced LHA from LGA in 3(5\%) cases; replaced RHA and LHA from SMA in $1(1.6 \%)$ case; LHA arising directly from the aorta in $1(1.6 \%)$ case.

One case had an exceptional anatomic variation, replaced LHA coming off the SMA directly to the hepatic left lobe (Fig. 1).

\section{DISCUSSION}

Anatomical variations of the arterial supply of the liver are not uncommon. Only half of the cases in anatomical 
studies have the typical normal anatomy of the hepatic artery $[10,11]$. Some of the variations such as the presence of a right or left hepatic branch arising from SMA and LGA respectively are more common, but others also relating to blood supply of the liver are extremely rare $[12,13]$.

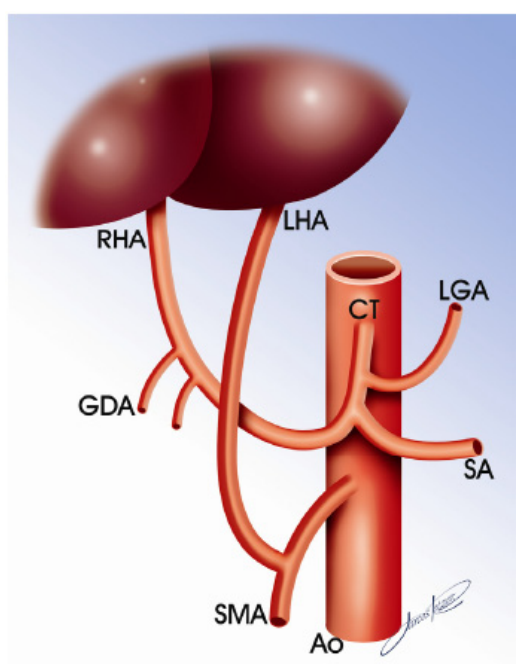

Fig. (1). Left hepatic artery coming off the superior mesenteric artery passing the hepatic hylum posteriorly to the common hepatic artery, heading upwards getting into the liver through the segment IV. RHA-right hepatic artery;GDA-gastroduodenal artery;SMAsuperior mesenteric artery;SA-splenic artery;LGA-left gastric artery;CT-celiac trunk; LHA-left hepatic artery.
Michels [5] reported a classification of 10 possible anatomical variants of the extra-hepatic arterial distribution that was based on a study of 200 autopsy cases. From a surgical point of view the classification is more complete since it establishes the differences between "an accessory" and "a replaced" artery, concepts not explained in more recent classifications.

Replaced hepatic arteries are anomalies that are easily managed, in contrast, the presence of accessory arteries might result in reconstructions of double arteries that, because of their small diameters, are the cause of an increased rate of arterial thrombosis in liver transplantation procedure despite the use of refined suture techniques $[14,15]$.

This study found that the LHA arose from the LGA in 10 (16.6\%) cases, according to literature replaced or accessory LHA range from 9.7 to $12 \%$ [16]. In one (1.6\%) case the CT arose from the SMA, this specific anatomical variation range from 1.1 to $1.5 \%$ [16].

LHA originating directly from the SMA as replaced artery is extremely rare anatomic variation, its incidence when originated from aorta range from 0.5 to $2 \%[12,13]$. Abdominal arteries arising from the superior mesenteric artery is shown in the Table $\mathbf{1}$. Moreover, the hepatic artery arising from the hepatic-mesenteric trunk and crossing the portal vein anterior to it has been described elsewhere [13].

Embryological CT and the SMA may have a common origin from the aorta (incidence approximately $1 \%$ ) or the trunk may have become a fibrotic string $[4,9]$. The arc of

Table 1. Literature Review of the Liver and Abdominal Arteries Arising from the Superior Mesenteric Artery

\begin{tabular}{|c|c|c|c|}
\hline Author & Year & Findings & Comments \\
\hline Abdullah et al. [19] & 2006 & RHA & 932 LTD \\
\hline Almenar-Garcia et al. [20] & 1993 & AcRHA & Case report \\
\hline Arjhansiri et al. [21] & 2006 & RHA & 200 angiography \\
\hline Covey et al. [22] & 2002 & PHA & 600 angiography \\
\hline Gruttadauria et al. [23] & 2001 & RHA & $701 \mathrm{LTD}$ \\
\hline Hiatt et al. [24] & 1994 & RHA & 1000 LTD \\
\hline Huu et al. [25] & 1976 & GDA & 400 cadaver dissection \\
\hline Iimura et al. [13] & 2007 & CHA & Case report \\
\hline Jones \& Hardy [26] & 2001 & RHA & 180 LTD \\
\hline Koops et al. [27] & 2004 & RHA & 604 LTD \\
\hline López-Andújar et al. [28] & 2007 & RHA & 1081 LTD \\
\hline Nagino et al. [29] & 1993 & RAHA & Case report \\
\hline Nayak et al. [30] & 2008 & IPDA & Case report \\
\hline Osawa et al. [31] & 2004 & CHA and IMA & Case report \\
\hline Pendarvis et al. [32] & 1997 & RA & Case report \\
\hline Ray et al. [33] & 1998 & LGA & Case report \\
\hline Sakamoto et al. [34] & 1999 & RGEA & Case report \\
\hline Yi et al. [35] & 2008 & IMA & Case report \\
\hline
\end{tabular}

RHA- right hepatic artery; AcRHA-accessory right hepatic artery; PHA- proper hepatic artery; GDA-gastroduodenal artery; IPDA- inferior pancreatico-duodenal artery; CHAcommon hepatic artery; RAHA- right anterior hepatic artery; IMA-inferior mesenteric artery; RA- renal artery; LGA-left gastric artery; RGEA-right gastroepiploic artery; LTD- liver transplantation donor. 
Buhler, i.e. a link vessel between the hepatic artery and the SMA, is not so unusual $[4,10]$, a seemingly more extraordinary situation is the case where a strong communicating artery between the CT and the SMA was found, on the other hand the RHA off the SMA occurs in up to $20 \%$ of all cases [2].

According to the theory of Tandler [17], the CA and the SMA develop as cephalic roots of vitelline or omphalomesenteric arteries, which are joined with a ventral paraaortic anastomosis between the 4th and 7th gestational weeks.

The embryological development of the liver starts in the 3rd gestational week as a hepatic diverticulum of the foregut [18]. The dorsal arteries join to form the aorta, from which paired branches provide a supply of blood to both the foregut and the liver bud. Since the primitive vitelline arteries form the CT and the SMA, one of these paired branches to the left of the foregut seems to have persisted in our case, creating a branch that irrigate the left lobe of the liver.

In conclusion, we would like to draw attention for this particularly anatomic variation of the origin of the LHA ensuring that no damage will be made during gastrointestinal surgery

\section{REFERENCES}

[1] Bertevello P, Chaib E. Hepatic artery system variations correlated to split-liver surgery: anatomic study in cadavers. Arq Gastroenterol 2002; 39(2): 81-5.

[2] Makisalo H, Chaib E, Krokos N, Calne RY -Hepatic arterial variations and liver-related diseases of 100 consecutive donors. Transpl Int 1993; 6(6): 325-9.

[3] Chen CY, Lee RC, Tseng HS, Chiang JH, Hwang JI, Teng MM. Normal and variant antomy of hepatic arteries: angiographic experience. Zhonghua Yi Xue Za Zhi(Taipei) 1998; 61(1): 17-23.

[4] Michels NA. Blood supply and anatomy of the upper abdominal organs. Lippincott, Philadelphia 1955.

[5] Michels NA. Newer anatomy of the liver and its variant blood supply and collateral circulation. Am J Surg 1966; 112: 337-47.

[6] Brems JJ, Millis JM, Hiatt JR, et al. Hepatic artery reconstruction during liver transplantation. Transplantation 1989; 47: 403-6.

[7] Decurtins M, Friend PJ, Calne RY. Incidence and outcome of donor arterial anomalies in liver allografts. Transplant Proc 1987; 29: 2394-5.

[8] Suzuki T, Nakayasu A, Kawabe K, Takeda H, Honjo I. Surgical significance of anatomic variations of the hepatic artery. Am J Surg 1971; 122: 505-12.

[9] Todo S, Makowka L, Tzakis AG, et al. Hepatic artery in liver transplantation. Transplant Proc 1987; 29: 2406-11.

[10] Blumgart LH. Surgery of the liver and biliary tract. Churchill Livingstone: Edinburgh 1988; pp. 31-37.

[11] Chaib E, Ribeiro Jr MAF, Saad WA, Gama-Rodrigues JJ -The main hepatic anatomic variations for the purpose of split-liver transplantation. Transplant Proc 37(2): 1063-6, 2005.

[12] Chaib E. Absence of bifurcation of the portal vein. Surg Radiol Anat 2009; 31(5): 389-92.

[13] Iimura A, Oguchi T, Shibata M, Takahashi T. Na anomalous case of the hepatic artery arising from the superior mesenteric artery. Okajimas Folia Anat Japan 2007; 84(2): 61-5.
[14] Marcos A, Ham JM, Fisher RA, Olzinski AT, Posner MP. Surgical management of anatomical variation of the right lobe in living donor liver transplantation. Ann Surg 2000; 231: 824-31.

[15] Nakamura T, Tanaka K, Kiuchi T, et al. Anatomical variations and surgical strategiesin right lobe living donor liver transplantation: lessons from 120 cases. Transplantation 2002; 73: 1896-903.

[16] Yamaoka Y, Washida M, Honda K, et al. Liver transplantation using a right lobe graft from a living related donor. Transplantation1994; 57: 1127-30.

[17] Tandler J. Uber die varietiten der Arteria Coeliaca und deren Entwicklung. Anat Hefte 25: 473,1904.

[18] Langman J. Medical embriology, $6^{\text {th }}$ ed. Baltimore, Philadelphia, MD, USA: Lippincott Willians \& Wilkins 1975; pp. 282-90.

[19] Abdullah SS, Mabrut JY, Garbit V, et al. Anatomical variations of the hepatic artey: study of 932 cases in liver transplantation. Surg Radiol Anat 2006; 28(5): 468-73

[20] Almenar-Garcia V, Sanchez del Campo F, Puchades Orts A, Cort Gomis A, Correa Lacarcel J. One further case of unusual origin of three hepatic arteries. Surg Radiol Anat 1993; 15(2): 155-7.

[21] Arjhansiri K, Charoenrat P, Kitsukjit W. Anatomic variations of the hepatic arteries in 200 patients done by angiography. J Med Assoc Thai 2006; 89(Suppl 3): S161-8.

[22] Covey AM, Brody LA, Malucio MA, Getrajdman GI, Brown KT. Variant hepatic arterial anatomy revisited: digital subtraction angiography performed in 600 patients. Radiology 2002; 224(2): 542-7.

[23] Gruttadauria S, Floglieni CS, Doria C, Luca A, Lauro A, Marino IR. The hepatic artery in liver transplantation and surgery: vascular anomalies in 701 cases. Clin Transpl 2001; 15(5): 359-63.

[24] Hiatt JR, Gabbay J, Busittil RW. Anatomy of the hepatic arteries in 1000 cases. Ann Surg 1994; 220(1): 50-2.

[25] Huu N, Tam NT, Minh NK. Gastro-duodenal artery arising from the superior mesenteric artery. Bull Assoc Anat 1976; 60(171)779-86.

[26] Jones RM, Hardy KJ. The hepatic artery: a reminder of surgical anatomy. J R Coll Surg Edinb 2001; 46(3): 168-70.

[27] Koops A, Wojciechowski B, Broering DC, Adam G, Krupski-Burdien G. Anatomic variations of the hepatic arteries in 604 selective celiac and superior mesenteric angiographies. Surg Radiol Anat 2004; 26(3): 239-44.

[28] Lopez-Andujar R, Moya A, Montalva E, et al. Lessons learned from anatomic variants of the hepatic artery in 1081 transplanted livers. Liver Transpl 2007; 13(10): 1401-4.

[29] Nagino M, Hayakawa N, Kitagawa S, Dohke M, Nimura Y. Right anterior hepatic artery arising from the superior mesenteric artery. Hepatogastroenterology 1993; 40(4): 407-9.

[30] Nayak SR, Prabhu LV, Krishnamurthy A, et al. Additional branches of celiac trunk and its clinical significance. Rom J Morphol Embryol 2008; 49(2): 247-9.

[31] Osawa T, Feng XY, Sasaki N, et al. Rare case of the inferior mesenteric artery and the common hepatic artery arising from the superior mesenteric artery. Clin Anat 2004; 17(6): 518-21

[32] Pendarvis RW, Slone HW, Fontaine AB. Renal artery origin from the superior mesenteric artery. J Vasc Interv Radiol 1997; 8(3): 480-1.

[33] Ray CE Jr, Gupta AK, Shenoy SS. Left gastric artery arising from the superior mesenteric artery-case reports. Angiology 1998; 49(12): 101721.

[34] Sakamoto H, Akita K, Sato T. Na anomalous right gartroepiploic artery arising from the superior mesenteric artery. Surg Radiol Anat 1999, 21(4): 283-6.

[35] Yi SQ, Li J, Terayama H, Naito M, IIimura A, Itoh M. A rare case of inferior mesenteric artery arising from the superior mesenteric artery, with a review of the literature. Surg Radiol Anat 2008 30(2): 159-65. 